\title{
DIRETRIZES POLÍTICAS DE INCLUSÃO ESCOLAR QUE DIRECIONAM O ACESSO NA EDUCAÇÃO INFANTIL EM MUNICÍPIOS GOIANOS
}

\author{
POLICY GUIDELINES FOR SCHOOL INCLUSION DIRECTING ACCESS TO CHILDREN \\ EDUCATION IN GOIAN MUNICIPALITIES
}

\author{
Monica Canuto ${ }^{\mathrm{I}}$ \\ Dulcéria Tartuci
}

\section{RESUMO}

O acesso e permanência das crianças público-alvo da educação especial na educação infantil é um direito subjetivo, portanto, deve ser garantido pelos sistemas municipais de ensino. Este artigo objetiva analisar as diretrizes políticas de seis municípios da Microrregião de Pires do Rio-Goiás GO, que direcionam ou não o acesso das crianças público alvo da educação especial na educação infantil. Refletindo que, ao adotar o paradigma de atendimento dessas crianças na rede regular de ensino, surgem demandas em relação às ações específicas de inclusão. Trata-se de uma pesquisa exploratória do tipo qualitativa que utilizou-se de análise documental e de roteiros de entrevistas semiestruturadas. Participaram do estudo seis secretários municipais de educação e seis diretores de instituições de educação infantil que tinham crianças público alvo da educação especial matriculadas neste nível de ensino. Os dados sinalizam que, mesmo sendo irrisório o número de matrículas na educação especial, houve uma elevação no ano de 2010, na maioria dos municípios. Em 83\% dos municípios constata-se que, as crianças público alvo da educação especial, não estão tendo garantido o seu direito social e humano de inserção escolar na creche. Os gestores demonstram não haver diretrizes políticas voltadas à educação especial e inclusão nos municípios pesquisados.

Palavras-chave: Educação Infantil. Inclusão. Acesso e Permanência.

\section{ABSTRACT}

The access and permanence of children targeted by special education in early childhood education is a subjective right, therefore, must be guaranteed by municipal education systems. This article aims to analyze the political guidelines of six municipalities in the Pires do Rio-Goiás GO Microregion, which direct or not the access of children targeted by special education in children's education. Reflecting that, when adopting the paradigm of care of these children in the regular network of education, demands arise in relation to the specific actions of inclusion. It is an exploratory research of the qualitative type that used documentary analysis and semi-structured interview scripts. Six municipal secretaries of education and six principals of early childhood education institutions that had special education target children enrolled at this level of education participated in the study. The data indicate that, even though the number of enrollments in special education is negligible, there was an increase in 2010 in most municipalities. In $83 \%$ of the municipalities, it is noted that the children targeted by special education are not guaranteed their social and human right to school in the day care center. The managers demonstrate that there are no policy guidelines for special education and inclusion in the cities surveyed.

Keywords: Child education. Inclusion. Access and Permanence.

\footnotetext{
I Mestranda do PPGEDUC - UFG - Regional Catalão e Docente da Universidade Estadual de Goiás. E-mail: monicacanuto08@gmail.com

II Docente do Departamento de Educação e do PPGEDUC da UFG - Regional Catalão. E-mail: dutartuci@brturbo.com.br Financiamento: Fundação de Amparo à Pesquisa do Estado de Goiás - FAPEG
} 


\section{INTRODUÇÃO}

As políticas sociais e educacionais brasileiras de atendimento às crianças ganharam maior visibilidade a partir dos anos finais da década de 1980. A aprovação da Lei nº. 8.069/1990, que dispõe sobre o Estatuto da Criança e do Adolescente - ECA, é um marco destas políticas. O ECA tem como um dos princípios que as crianças são sujeitos de direitos fundamentais e individuais (BRASIL, 1990).

Em relação às políticas educacionais, atualmente as Diretrizes Curriculares Nacionais para a Educação Infantil - DCNEI (2010) reafirmam o direito social das crianças quanto ao atendimento em creches e pré-escolas, reconhecendo essa etapa educacional como dever do Estado. Determinam também que as crianças tenham vivências éticas e estéticas com outras crianças e grupos culturais, as quais possibilitarão o reconhecimento da diversidade (BRASIL, 2010).

Segundo o Resumo Técnico do Censo Escolar da Educação Básica (Inep, 2012) as matrículas na creche aumentaram 10,5\% entre 2011 e 2012, sendo que 63,1\% do total estão concentrados nas redes municipais de ensino. A expansão das matrículas na pré-escola não seguiu a mesma tendência da creche, uma vez que houve um aumento de somente 1,6\% (BRASIL, 2012).

No ano de 2012, as creches brasileiras detinham um total de dois milhões quinhentos e quarenta mil setecentos e noventa uma (2.540.791) crianças de zero a três anos, enquanto a pré-escola detinha um total de quatro milhões setecentos e cinquenta e quatro mil setecentos e vinte e uma (4.754.721) crianças de quatro a cinco anos. $\mathrm{O}$ que totaliza sete milhões duzentos e noventa e cinco mil quinhentos e doze (7.295.512) crianças matriculadas na educação infantil (BRASIL, 2012).

Em Goiás, foco dessa pesquisa, de acordo com o Censo Demográfico de 2010, o Estado possuía naquele período uma população de seiscentos e vinte e três mil duzentos e oitenta e quatro (623.284) crianças na faixa dos zero a seis anos. Destas somente duzentas e cinquenta e nove mil e setecentas e vinte (259.720) frequentavam a creche ou escola, de zero a seis anos, representando um percentual em torno de $41,6 \%$.

Em relação ao atendimento às crianças público alvo da educação especial, são instituídas as Diretrizes Curriculares Nacionais para a Educação Especial na Educação Básica DCNEE-EB, em 2001 como consequência da Lei de Diretrizes e Bases da Educação Nacional (LDBEN) 9394/96 que determina o atendimento deste público preferencialmente na rede regular de ensino. Elas indicam que, o acesso destas crianças tenha início na educação infantil, em creches e pré-escolas, cabendo às escolas se organizarem para oferecer este atendimento (BRASIL, 2001).

De Vitta (2010) discorre que, a perspectiva da educação inclusiva pode ocorrer de maneira mais natural no espaço da educação infantil, tanto pelas características inerentes a esta etapa do processo educacional, quanto pelos aspectos ligados ao desenvolvimento infantil. Para Melo e Ferreira (2009), a educação infantil é a porta de 
entrada para a inclusão escolar, sendo este nível marcado pelo desenvolvimento integral da criança, pois elas interagem com mais liberdade sem estar presas a um currículo a ser cumprido.

Essas experiências promovem o pleno desenvolvimento da criança, contribuem para a aquisição de habilidades e a superação de dificuldades. Sua inserção também possibilita à criança compreender o ambiente social e se localizar nele, o qual é composto pela diversidade humana (DE VITTA, 2010). Entretanto, existe uma demanda por pesquisas que demonstrem, a curto prazo, a importância dessas experiências precoces e de qualidade para o desenvolvimento cognitivo, emocional e social da criança e, a longo prazo, para seu sucesso na escola e na vida (ECPI/OCDE, 2002).

A inserção das crianças na educação infantil, especialmente o público alvo da educação especial, é uma conquista social e humana, que contribui decisivamente para o desenvolvimento afetivo, social, cognitivo, emocional e físico de todas elas. De acordo com o Resumo Técnico do Censo Escolar da Educação Básica (INEP, 2012), o total de crianças público alvo da educação especial matriculadas na educação infantil, no ano de 2012, foi de dezoito mil seiscentos e cinquenta e dois (18.652) nas classes especiais e escolas inclusivas, e de quarenta mil quatrocentos e cinquenta e seis (40.456) nas classes comuns.

Os números mostram uma tendência, mesmo que baixa, de aumento no quantitativo de crianças público alvo da educação especial, atendidas nas instituições de educação infantil. Possivelmente, porque as políticas educacionais a partir de 2008, como por exemplo, a Política Nacional de Educação Especial - PNEE de 2008, tenham contribuído decisivamente para este aumento, como também, a pressão dos diferentes grupos sociais, para que estas crianças tivessem garantido o seu direito social e humano de frequentar a escola.

As políticas públicas educacionais de acesso e permanência de todas as crianças na educação infantil estão postas. Pesquisadores e estudiosos defendem a importância da educação infantil e do e o Atendimento Educacional Especializado (AEE) para essas crianças, resta saber se estão matriculadas.

Diante deste cenário buscou-se dados que permitissem responder: As crianças de zero a cinco anos, público-alvo da educação especial, estão tendo acesso à educação infantil? Neste sentido essa pesquisa teve por objetivo analisar as diretrizes políticas de seis municípios da Microrregião de Pires do Rio-Goiás GO, que direcionam ou não o acesso das crianças público alvo da educação especial na educação infantil.

Os estudos sobre a presença de crianças, público alvo da educação especial, nas instituições de educação infantil, têm sido publicados com mais ênfase a partir de 2007, trazendo valiosas contribuições aos pesquisadores e estudiosos da área.

As pesquisas demonstram, dentre os benefícios e contribuições da educação inclusiva para todas as crianças, o importante papel da interação entre alunos-alunos, professor-aluno, enfim, toda a comunidade escolar. Ou seja, a escola inclusiva deve promover as possibilidades e potencialidades de todos os alunos, sendo que, 
a relação entre professor e aluno com deficiência deve influenciar a autoimagem dele e a forma como os colegas o veem, trazendo benefícios para todos e influenciando no sucesso da aprendizagem (FARIAS et.al., 2008).

Reforçando a importância da criança público alvo da educação especial ser matriculada na educação infantil, Sekkel et.al. (2010) acreditam que, a convivência das crianças sem deficiência com o público alvo da educação especial, juntamente com a equipe escolar envolvida com o trabalho, pode ter um poder transformador nas relações, cuja consequência é a diminuição do preconceito e a valorização das diferenças.

\section{METODOLOGIA}

Os dados aqui apresentados é um recorte de uma pesquisa de Mestrado ${ }^{1}$, trata-se de uma pesquisa qualitativa, com base nos estudos de Bogdan e Biklen (1994).

Para tanto, estabeleceu-se como o corpus de pesquisa os sistemas municipais de ensino (SME) e as instituições de educação infantil dos municípios da Microrregião de Pires do Rio, a saber: Ipameri, Orizona, Palmelo, Pires do Rio, Santa Cruz de Goiás e Urutaí.

Os procedimentos da investigação envolveram a análise documental e entrevistas semiestruturadas. Quanto aos documentos analisados foram: planos municipais de educação, orientações normativas sobre a educação especial no município e projetos político-pedagógicos.

1 Crianças Público Alvo da Educação Especial na Educação Infantil aprovada pelo Comitê de Ética do Instituto Federal Goiano por meio do Parecer Consubstanciado de $n^{\circ}$ 035/2013.
As entrevistas semiestruturadas foram realizadas com seis secretários municipais de educação, uma coordenadora de educação especial e seis diretores de instituições de educação infantil, no segundo semestre de 2013. O roteiro de entrevista elaborado foi validado pelos membros do Núcleo de Pesquisa em Práticas Educativas e Inclusão (NEPPEIn) e pelos professores integrantes da linha de pesquisa "Práticas Educativas, Políticas Educacionais e Inclusão" do Programa de Pós-Graduação em Educação, ambos da Universidade Federal de Goiás - UFG / Regional Catalão.

Analisou-se a partir dos conteúdos e temas abordados, as políticas, as ações, as diretrizes e as condições de acesso e permanência das crianças público alvo da educação especial na educação infantil, procurando apreender a realidade dos seis municípios da Microrregião de Pires do Rio-GO, no que se refere ao atendimento das crianças menores, público alvo da educação especial.

\section{RESULTADOS E DISCUSSÃO}

Optamos por apresentar, a princípio, os dados quantitativos de acesso das crianças público-alvo da educação especial na educação infantil, entre os anos de 2007 a 2013 e também as diretrizes das secretarias municipais de educação que direcionam o acesso e a permanência desse público.

\section{A evolução das matrículas das crianças menores na educação infantil e daquelas público-alvo da educação especial}

Quanto ao acesso das crianças público alvo da educação especial na educação infantil, no 
Estado de Goiás, o Censo só começou a registrar estes dados a partir de 2007. Nos anos anteriores foi computado somente o total geral de alunos da educação especial e dos alunos matriculados no ensino fundamental.

Sobre o índice de crianças público alvo da educação especial, atendidas na educação infantil, nos municípios da Microrregião de Pires do Rio, os dados consultados foram de 2007 a 2013. Pois, somente a partir de 2007, passaram a ser registrados no Censo Escolar o número de atendimento deste público na educação infantil. A seguir, a tabela 1 traz os dados de acesso das crianças publico alvo da educação especial na educação infantil, nos municípios da Microrregião de Pires do Rio.

Tabela 1 - Número de matrículas da educação especial na educação infantil nos municípios da Microrregião de Pires do Rio, de 2007 a 2013.

\section{Educação Especial na Educação Infantil}

\begin{tabular}{|l|c|c|c|c|c|c|}
\hline Anos & & & & & & \\
\hline Municípios & 2007 & 2008 & 2009 & 2010 & 2011 & 2012 \\
\hline Ipameri & 21 & 34 & 39 & 58 & 54 & 30 \\
\hline Orizona & 01 & 0 & 0 & 02 & 02 & 01 \\
\hline Palmelo & 0 & 0 & 0 & 01 & 01 & 01 \\
\hline Pires do Rio & 02 & 01 & 01 & 01 & 03 & 03 \\
\hline $\begin{array}{l}\text { Santa Cruz } \\
\text { de Goiás }\end{array}$ & 0 & 0 & 0 & 0 & 0 & 0 \\
\hline Urutaí & 0 & 0 & 0 & 01 & 03 & 02 \\
\hline Total: & $\mathbf{2 4}$ & $\mathbf{3 5}$ & $\mathbf{4 0}$ & $\mathbf{6 3}$ & $\mathbf{6 3}$ & $\mathbf{3 7}$ \\
\hline
\end{tabular}

Fonte: MEC/INEP. Censo Escolar da Educação Básica: microdados (2007 a 2013). Acesso em: 10/04/2014.

Mesmo sendo irrisório o número de matrículas na educação especial, os dados demonstram que, houve uma elevação no ano de 2010, na maioria dos municípios. Ressaltandose que, em 2008, não havia matrícula de crianças público alvo da educação especial em boa parte deles.

Faz-se relevante analisar separadamente os dados de matrícula de crianças público alvo da educação especial, da creche e da pré-escola, a fim de verificar qual a faixa etária da educação infantil está sendo mais atendida, conforme a tabela 2, a seguir, demonstra.

Tabela 2 - Número de matrículas de crianças público alvo da educação especial na creche e na pré-escola, nos municípios da Microrregião de Pires do Rio.

\begin{tabular}{|c|c|c|c|c|c|c|c|c|c|c|c|c|c|c|}
\hline & \multicolumn{7}{|c|}{ Creche } & \multicolumn{7}{|c|}{ Pré-escola } \\
\hline & \multicolumn{7}{|c|}{ Anos } & \multicolumn{7}{|c|}{ Anos } \\
\hline Municípios & 용 & ஓ̊ & ஓे & $\frac{0}{\stackrel{0}{\delta}}$ & $\overline{\bar{\delta}}$ & $\frac{\mathrm{N}}{\mathrm{D}}$ & $\frac{m}{i}$ & 용 & $\begin{array}{l}\infty \\
\text { 유 }\end{array}$ & ஓి & $\stackrel{\circ}{\circ}$ & $\bar{\Xi}$ & $\frac{N}{8}$ & $\frac{m}{\rho}$ \\
\hline Ipameri & 09 & 14 & 16 & 16 & 09 & 04 & 03 & 122 & 202 & 234 & 424 & 45 & 26 & 06 \\
\hline Orizona & 0 & 0 & 0 & 0 & 0 & 0 & 0 & 01 & 0 & 00 & 020 & 02 & 01 & 01 \\
\hline Palmelo & 0 & 0 & 0 & 01 & 01 & 01 & 0 & 0 & 0 & 0 & 0 & 0 & 0 & 0 \\
\hline Pires do Rio & 0 & 0 & 0 & 0 & 0 & 0 & 0 & 020 & 010 & 010 & 01 & 03 & 03 & 02 \\
\hline $\begin{array}{l}\text { Santa Cruz } \\
\text { de Goiás }\end{array}$ & 0 & 0 & 0 & 0 & 0 & 0 & 0 & 0 & 0 & 0 & 0 & 0 & 0 & 0 \\
\hline Urutaí & 0 & 0 & 0 & 0 & 0 & 0 & 0 & 0 & 0 & 00 & 01 & 03 & 02 & 0 \\
\hline Total: & 09 & 14 & 16 & 17 & 10 & 05 & 03 & 152 & 212 & 244 & & 53 & 32 & 09 \\
\hline
\end{tabular}

Em $83 \%$ dos municípios constata-se que, as crianças público alvo da educação especial, não estão tendo garantido o seu direito social e humano de inserção escolar na creche. Desta forma, as crianças perdem a oportunidade de serem estimuladas e se desenvolverem satisfatoriamente.

Partimos do pressuposto que a não inserção das crianças de zero a três anos na creche, inclusive aquelas que são público alvo da educação especial, acarreta prejuízos no desenvolvimento destas crianças. Sabemos que as crianças, que nascem com alguma deficiência ou limitação em seu desenvolvimento, necessitam do estímulo de profissionais para que a mesma possa superar tais limitações e também conviver, aprender e interagir com seus pares. 
É preocupante saber que, dos seis (06) municípios investigados somente Ipameri e Orizona atenderam crianças público alvo da educação especial na creche, entre os anos de 2007 a 2013. Os dados evidenciam que a inclusão nos municípios pesquisados está acontecendo com maior ênfase na pré-escola.

Os dados de acesso de todas as crianças menores na educação infantil, ressaltam que, mesmo sendo considerada essencial para o desenvolvimento pleno das crianças, a educação infantil ainda não está universalizada. A este respeito Bueno e Meletti (2011, p. 286) alerta que:

Se quisermos, efetivamente, aprimorar os processos inclusivos de educação para alunos com deficiência, com busca crescente da melhoria da qualidade de ensino, não podemos manter estes níveis, tanto de escolarização quanto de inclusão escolar na educação infantil, sob a pena de mantermos aquilo que tanto temos criticado: a simples absorção desses alunos para a melhoria dos índices estatísticos, mas sem a necessária qualidade que contribua para a construção de sua cidadania.

A educação inclusiva pode ocorrer de maneira mais natural no espaço da educação infantil, tanto pelas características inerentes a esta etapa do processo educacional, quanto pelos aspectos ligados ao desenvolvimento infantil. O que contribui para a estimulação da criança com deficiência e também a prevenção de déficits no desenvolvimento das crianças que vivem em ambiente de risco (DE VITTA, 2010).

A educação infantil é a porta de entrada para a inclusão escolar, sendo este nível marcado pelo desenvolvimento integral da criança, onde elas interagem com mais liberdade sem estar presas a um currículo a ser cumprido (MELO; FERREIRA, 2009).

O acesso é um dos aspectos da política educacional e é um direito inerente a todo cidadão brasileiro independente de sua condição física, sensorial, emocional, social e cultural. Contudo, é necessário conhecer o que vem direcionando $\mathrm{o}$ direito à matrícula e à permanência exitosa das crianças com deficiência, transtornos globais do desenvolvimento e altas habilidades ou superdotação na educação infantil. Para tanto, buscar-se-á identificar e caracterizar as diretrizes políticas dos municípios goianos investigados, que tratam da educação destas crianças.

\section{As diretrizes existentes nas secretarias municipais de educação e nas instituições de educação infantil}

As diretrizes legais sobre o atendimento das crianças público-alvo da educação especial na educação infantil foram analisadas a partir dos documentos existentes nas secretarias municipais de educação e nas escolas. No primeiro contato da pesquisadora com estas secretarias, em especial com os secretários, verificou-se que, dos seis municípios que fizeram parte desta pesquisa somente dois possuíam Plano Municipal de Educação (PME) até o ano de 2013, sendo eles: Orizona e Santa Cruz de Goiás.

Nas seis instituições de educação infantil pesquisadas, os gestores afirmaram ter o Projeto Político Pedagógico (PPP) porém, somente cinco (05) delas forneceram-no para posterior análise.

O PME de Orizona destina um capítulo específico para a educação especial, uma vez que, 
“esse problema é complexo e exige soluções diferenciadas, mesmo porque as necessidades especiais são variáveis" (ORIZONA, 2001, p.05). Todavia, ressalta que, o atendimento das crianças público alvo da educação especial é problemático, porque a rede municipal não possui infraestrutura adequada para receber este público.

Analisando as referidas metas do PME de Orizona (2001), verifica-se que há uma indefinição em relação ao termo utilizado para denominar o público alvo da educação especial. Ora são citados como "portadores de necessidades especiais", ora como "educandos com necessidades educativas especiais" e, por fim, como "necessidades especiais". Conquanto, o PME de Orizona é um avanço em termos de diretrizes políticas para a educação municipal, mesmo porque a data de sua aprovação se articula com a aprovação das diretrizes de 2001, do MEC.

O PME de Santa Cruz de Goiás foi aprovado em 2009, por meio da Lei $\mathrm{n}^{\circ}$. 568/2009. Traz como prioridades, dentre outras, ampliar o atendimento da educação infantil e garantir ao público alvo da educação especial, o acesso a uma educação de qualidade em todos os níveis de ensino. Em relação a educação infantil define que

Uma instituição de educação infantil deve, de forma inclusiva, promover o acesso indiscriminado a todas as crianças, ampliando a oferta de vagas para esta faixa etária, no município de Santa Cruz de Goiás. Dessa forma, são necessários que se busquem recursos financeiros junto ao Governo Federal, que contemplem a educação infantil. (PME/Santa Cruz de Goiás, 2009, p.10).
Nestas diretrizes estabelecidas para a educação infantil, percebe-se a preocupação e o reconhecimento da necessidade de ampliação do atendimento deste nível de ensino. Mesmo sabendo que, as crianças de zero a três anos não têm acesso à creche neste município, esta ampliação faz-se necessária e urgente.

Embora o Plano Nacional de Educação (PNE) (2001-2011) tenha definido no Capítulo V - Financiamento e Gestão - como um dos objetivos a elaboração e execução de planos estaduais e municipais de educação, em consonância com este plano, doze anos após sua aprovação quatro municípios, dentre os seis pesquisados, ainda não elaboraram seus planos municipais de educação.

A ausência de diretrizes políticas por parte de 04 municípios dificulta a percepção de como está sendo a oferta de atendimento das crianças público alvo da educação especial na educação infantil. Por isso, a análise dos PPP das escolas participantes da pesquisa propiciou conhecer o que está sendo oferecido para as crianças e o público alvo da educação especial nas instituições de educação infantil.

A LDBEN nº. 9394/96, em seu Artigo 12, definiu como incumbência das escolas elaborarem e executarem a sua proposta pedagógica, dando-lhes a autonomia e a responsabilidade para escolher que tipo de ensino querem e irão ofertar aos seus alunos. Deste modo, no PPP a comunidade escolar expressa as concepções que irão nortear suas ações pedagógicas.

Se o PPP da instituição expressa as concepções, traça as diretrizes de ações e os 
procedimentos, é importante identificar como a educação e inclusão das crianças público alvo da educação especial está presente neste documento. Desta forma, a análise deles ocorreu com foco na filosofia educacional, objetivos e ações específicas de inclusão. Além do PPP, foram considerados na discussão os aspectos sobre o tema apresentados nas entrevistas com os diretores das instituições de educação infantil.

$\mathrm{Na}$ análise dos PPP das seis instituições de educação infantil, investigadas na Microrregião de Pires do Rio, ressaltamos que, das duas escolas participantes da pesquisa em Ipameri, somente o CIPO disponibilizou o seu PPP. Este projeto foi elaborado em 2013 e tem como missão:

Proporcionar ao educando desenvolvimentos intelectuais, emocionais, físicos e sociais, ajudando a construir além da aprendizagem, valores baseados nos ideais de solidariedade humana, respeito e amor ao próximo, garantindo-lhes assim a oportunidade do real exercício da cidadania e preparando-os para o futuro sucesso no âmbito educacional. (PPP/CIPO, 2013 p.03).

Esta instituição de ensino demonstra em seu PPP (2013) a preocupação em estimular a autonomia das crianças, despertar a criticidade e trabalhar valores essenciais para a convivência harmoniosa, tanto na escola como na sociedade. Acreditam que, o aluno é a própria razão de ser da escola.

Porém, as leituras e análises feitas no PPP (2013) do CIPO não evidenciaram haver um trabalho direcionado às crianças público alvo da educação especial, nem demonstraram as condições de permanência oferecidas a elas. O que é reforçado com a fala da diretora durante a entrevista, quando questionada de que modo a educação e inclusão das crianças público alvo da educação especial é contemplada no PPP da instituição:

"Nós recebemos o João em julho então eu
não vou mentir para você, a gente não
esperava o João e nós não fizemos previsão
nenhuma neste ponto". (Diretora CIPO,
2013.)

Em Orizona, o CMLC elaborou o seu PPP de 2013, trazendo como filosofia a valorização das potencialidades das crianças, adolescentes e jovens, estimulando o pleno desenvolvimento rumo à construção da própria identidade. Interessante observar que, este projeto expressa em um dos seus objetivos: "oferecer estimulação adequada nos aspectos psicomotor, afetivo, cognitivo, etc, respeitando-se o ritmo de cada educando e oferecendo condições ambientais e educativas que incentivem a criatividade" (PPP/CMLC, 2013 p.07), objetivo este que vai ao encontro do atendimento das crianças público alvo da educação especial na educação infantil, cuja estimulação é tão necessária para esta faixa etária.

Apesar de ser citado pela diretora que, uma das grandes dificuldades enfrentadas pela escola ao atender as crianças público alvo da educação especial, é a falta de espaço físico adequado, ela não aparece no PPP, quando relaciona as fragilidades da escola. Contudo, o PME de Orizona (2001) ressalta a necessidade de criar infraestrutura para o atendimento deste público.

Em entrevista a diretora do CMLC, foi questionada de que modo a educação e a inclusão das crianças público alvo da educação especial é contemplada no PPP da instituição. Ela asseverou 
que:

“Tudo que nós temos no PPP é pra eles, é através de danças, nós temos jogos, entra mais essa parte lúdica praticamente é isso ai que nós temos no PPP pra eles." (Diretora CMLC, 2013).

Mesmo tendo afirmado que, todas as ações são também para as crianças público alvo da educação especial, o PPP não retrata esta afirmativa, porque não aborda especificamente ações para a garantia das condições de permanência destas crianças na instituição, muito menos a concepção de educação especial e inclusão que norteia o trabalho da instituição com este público em específico.

O PPP de 2013, da CJD em Pires do Rio, expressa a filosofia da instituição, expondo que, "a escola deve ser um espaço lúdico de aprendizagem, de forma a ampliar as experiências, valorizar a iniciativa e curiosidade, contribuindo para a construção do conhecimento" (PPP/CJD, 2013 p.02). Também aborda a discussão da inclusão na educação infantil, ressaltando que a educação especial articula-se a ela no sentido de garantir oportunidades socioeducacionais às crianças. Acredita que,

A inclusão precisa ser atendida como o espelho da educação, um direito adquirido, que consiste em oferecer uma formação que acompanhe o aprendizado regular, estabelecendo políticas claras e garantias de condições para que elas sejam implementadas. Para isso, o centro deverá adaptar-se a essa realidade, assim todos terão a oportunidade de desenvolver ao máximo suas potencialidades (PPP/CJD, 2013, p.04).

A instituição de ensino manifesta ter clara a ideia do direito da criança, público alvo da educação especial, em acessar a escola através da garantia de uma vaga e o direito de permanecer, aproveitando as condições e oportunidades de desenvolvimento de suas potencialidades propiciadas pela escola.

De acordo com a diretora, ao ser questionada sobre o modo que a educação e a inclusão das crianças público alvo da educação especial é contemplada no PPP da instituição, declarou que:

Não tem nenhuma parte voltada para eles não, nós não fizemos nenhuma parte voltada para eles não, primeiro porque nós só tínhamos um caso, se bem que isso não justifica, depois que apareceu os outros dois. Então, a gente realmente tem que rever esse nosso PPP para fazer uma coisa voltada para eles. (Diretora CJD, 2013).

Ao ler o PPP (2013) da CMMT em Pires do Rio, averiguou-se que, esta instituição definiu que a creche e a pré-escola têm como objeto as relações educativas travadas num espaço de convívio coletivo, tratando a criança como sujeito. Lembrando que, a instituição de ensino tem como filosofia educacional:

\begin{abstract}
A criança é percebida como um ser ativo, atento e criativo, elaborando hipóteses sobre seu ambiente dentro e fora da escola. Portanto, durante a seleção e desenvolvimento das atividades que fazem parte da organização do processo ensinoaprendizagem, a escola preocupa-se na adequação a cada faixa etária e suas necessidades específicas, bem como os estágios de desenvolvimento cognitivo (PPP/CMMT, 2013 p.02).
\end{abstract}

Em seu PPP, a respectiva instituição não se refere à educação especial e inclusão, nem traça ações para garantir a permanência das crianças público alvo da educação especial, apesar de ter uma criança nessas condições matriculada na préescola. Esta inexistência é também reforçada pela diretora, em entrevista, a qual afirmou que: 
Eu sinto que nós falhamos neste sentido porque quando fizemos o PPP no inicio do ano, logo depois detectamos o problema da criança. Eu creio que para o ano que vem esse PPP tem que ser mudado nesse sentido para que através desse documento a gente possa até conseguir resolver esses problemas (Diretora CMMT, 2013).

Em Santa Cruz de Goiás, a EMAL elaborou o seu PPP em 2013, propondo como missão a oferta de uma educação eficaz, capaz de formar cidadãos atuantes e habilitados para viver numa sociedade globalizada, individualista e tecnológica. Dentre as metas a serem alcançadas na instituição, expressas no PPP (2013), destacam-se: “Garantir o acesso das crianças com necessidades educacionais especiais na instituição". (PPP/EMAL, 2013 p.12).

Em entrevista, ao ser questionada de que modo a educação e inclusão das crianças público alvo da educação especial é contemplada no PPP da instituição, a diretora ressaltou que: "é contemplado sim no PPP, fala do direito que eles têm a professor de apoio" (Diretora EMAL, 2013). Porém, no PPP não foram encontradas informações sobre o direito do público alvo da educação especial ao professor de apoio, conforme mencionado pela diretora.

As análises dos documentos elaborados pelas SME e pelas instituições de educação infantil permitiu apreender que, as diretrizes que contribuiriam para a garantia de acesso e permanência das crianças público alvo da educação especial, não são estão postas. Assim como, na maioria dos municípios da Microrregião de Pires do Rio pesquisados, há ausência significativa de políticas públicas voltadas à educação especial e inclusão o que

compromete na qualidade do ensino ofertada a este público.

Uma vez analisadas as diretrizes políticas tanto das SME, bem como dos PPP das cinco instituições de educação infantil participantes da pesquisa, nota-se que, tais diretrizes influenciam no acesso e permanência das crianças público alvo da educação especial na educação infantil.

Indo ao encontro da realidade das SME, a reflexão acerca das falas dos gestores -secretários municipais e coordenadora de educação especial, a partir das entrevistas realizadas, é possível compreender melhor como estão sendo pensadas as políticas públicas voltadas à educação especial e inclusão nos municípios da Microrregião de Pires do Rio. Ao serem questionados sobre o tema, os referidos gestores fizeram as seguintes afirmativas, conforme Quadro 1 a seguir:

\begin{tabular}{|c|c|}
\hline \multicolumn{2}{|c|}{ 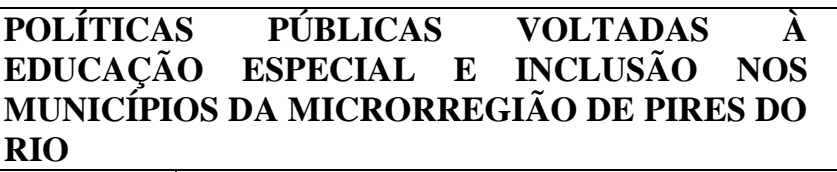 } \\
\hline Município & Visão dos participantes \\
\hline Ipameri & $\begin{array}{l}\text { Nós ainda não temos nada regulamentado, a } \\
\text { única coisa que a gente tem é a obrigação de } \\
\text { receber essas crianças. (Secretária } \\
\text { Municipal de Educação) }\end{array}$ \\
\hline Orizona & $\begin{array}{l}\text { Nós estamos aprendendo e não estamos } \\
\text { medindo esforços para ajeitar tudo que é } \\
\text { preciso, sala e aparelhos, tudo que é } \\
\text { necessário o município de Orizona tem } \\
\text { tentado fazer. (Secretário Municipal de } \\
\text { Educação) }\end{array}$ \\
\hline Palmelo & $\begin{array}{l}\text { A gente tem a } L D B \text { e o PPP, é a questão } \\
\text { mais curricular mesmo. (Secretária } \\
\text { Municipal de Educação) }\end{array}$ \\
\hline $\begin{array}{l}\text { Pires do } \\
\text { Rio }\end{array}$ & $\begin{array}{l}\text { Tem alguns direcionamentos que a gente } \\
\text { pegou, de apostilas de formação do Estado, } \\
\text { a gente está esperando as coisas se } \\
\text { consolidarem. (Secretária Municipal de } \\
\text { Educação) }\end{array}$ \\
\hline $\begin{array}{l}\text { Santa } \\
\text { Cruz }\end{array}$ & $\begin{array}{l}\text { Não, porque na realidade nós não temos } \\
\text { muito, esse público é bem mínimo então nós } \\
\text { vamos lidar com os casos que aparecem } \\
\text { pontualmente, nós não temos nenhum } \\
\text { objetivo traçado porque é mínimo. } \\
\text { (Secretário Municipalde Educação) }\end{array}$ \\
\hline Urutaí & $\begin{array}{l}\text { Neste ponto o município é bem carente, } \\
\text { precisar aprimorar muito. } \quad \text { (Secretário }\end{array}$ \\
\hline
\end{tabular}




\section{Municipal de Educação)}

Fonte: Quadro elaborado pela autora com base nos dados advindos das entrevistas.

De maneira geral, os gestores demonstram não haver diretrizes políticas voltadas à educação especial e inclusão nos municípios pesquisados. Se o município não as adota, porque o público é mínimo, os gestores revelam um discurso excludente, demonstrando despreocupação com o acesso e permanência das crianças público alvo da educação especial na educação infantil.

É instigante perceber que, mesmo após uma década de implantação da política de educação inclusiva, em nível nacional e estadual, os gestores em sua maioria declararam estar sem direcionamento. A análise dos relatos deixa claro que, não há regulamentação da educação especial e inclusão nas SME.

A adoção de políticas educacionais voltadas à educação especial e inclusão é o primeiro passo, para que o município oportunize o acesso e a permanência das crianças público alvo da educação especial, reconhecendo sua existência e seus direitos civis, sociais e humanos. Mendes (2010b) ao investigar a possibilidade e a viabilidade da inclusão escolar começar pelas creches, define como marco zero para implementação de práticas inclusivas, sendo a creche a porta de entrada para o sistema educacional.

De Vitta (2010, p. 79) ao discutir sobre a inclusão na educação infantil afirma que:

A Educação Infantil, especialmente o berçário, parece ser o estágio cuja perspectiva inclusiva pode ocorrer de forma mais natural, tanto pelas características particulares inerentes a essa etapa do processo educacional, quanto pelos aspectos desenvolvimentais dessa faixa etária.

Nesta perspectiva, a creche representaria um rico espaço de estimulação e prevenção de déficits, contribuindo para o desenvolvimento das crianças de forma satisfatória. Entendemos que, vários são os aspectos que dificultam o trabalho nas creches com todas as crianças, porém a inclusão de todas elas é uma conquista a ser alcançada.

Sobre o paradigma da educação inclusiva, Farias et al. (2008) entendem que, não deveria mais estar discutindo a inclusão das pessoas com deficiência no contexto educacional, uma vez que o acesso à educação é um direito de todos. Posto que, a inclusão deve ser instituída radical, completa e sistematicamente, cuja escola se reorganiza para atender as necessidades individuais de todos os alunos.

As ações nascidas posteriormente à adoção de políticas, caso sejam fruto da mobilização de todos os envolvidos com o processo educacional, representarão a preocupação política, ética e humana dos gestores municipais em relação àquela parcela da população considerada minoritária por muitos. Todavia, significativa e por séculos desconsiderada como sujeito de direitos, assim como, merecedora de uma real atenção e de uma educação de qualidade, justa e igualitária.

\section{CONSIDERAÇÕES FINAIS}

A respeito das diretrizes que direcionam o acesso e permanência das crianças público alvo da educação especial na educação infantil, percebe-se que ainda é algo inexistente nos 
municípios que fizeram parte deste estudo, contudo, verificou-se, por meio dos relatos, que os gestores sabem da importância da adoção de políticas que garantam este direito às crianças menores.

Sabemos que as diretrizes influenciam diretamente nas ações adotadas no interior das instituições de educação infantil e os dados nos permitiram perceber que as condições de permanência ofertadas às crianças público alvo da educação especial são as mesmas para as outras crianças.

Nos municípios goianos, foco dessa pesquisa, as matrículas das crianças público alvo da educação especial na educação infantil são mínimas e corroboram com os dados nacionais. $\mathrm{O}$ acesso delas ocorre muito mais na pré-escola do que na creche e há a precariedade das condições oferecidas a elas, para que possam se desenvolver e aprender.

Em relação à quantidade de crianças público alvo da educação especial matriculadas na educação infantil, é possível perceber que, as políticas e diretrizes educacionais municipais não estão cumprindo com a garantia do direito de todas as crianças ao acesso a este nível de ensino. Situação claramente retratada nos municípios da Microrregião de Pires do Rio, com um percentual de $2,01 \%$.

Nesta linha de discussão, encontramos em Bueno e Meletti (2011) a afirmação de que, as políticas educacionais têm dado pouca relevância em relação ao acesso de crianças com deficiência na educação infantil. Acreditamos que, os sistemas de ensino municipais devem, a princípio, assegurar vagas para as crianças público alvo da educação especial em todos os níveis da educação, especialmente na educação infantil, o primeiro passo à escolarização.

Bueno e Meletti (2011, p. 285) argumentam que é preciso estabelecer "políticas federais que induzam a ampliação de matrículas de alunos com deficiência, nas creches e pré-escolas, tal como se fez com as políticas de indução da inclusão desses alunos no ensino fundamental, especialmente a partir de 2008”. Desta forma, as crianças público alvo da educação especial teriam seu direito de acesso na educação infantil garantido, uma vez que este nível de educação para todas as crianças já é plenamente reconhecido.

Outro aspecto a ser discutido em relação ao acesso é que, a matrícula de crianças público alvo da educação especial na educação infantil, ocorre em maior número na pré-escola. Do total de crianças público alvo da educação especial matriculadas na educação infantil, de 2008 a 2012, nos municípios da Microrregião de Pires do Rio, somente $26,3 \%$ estão nas creches.

Sabemos que, na faixa etária de 0 a 3 anos, o processo de desenvolvimento das crianças deve ser estimulado para o desenvolvimento cognitivo, socioafetivo, motor e a prevenção de futuros déficits. Assim, é necessário que sejam feitas parcerias entre Secretarias de Saúde e de Educação para o encaminhamento de crianças da educação especial aos serviços especializados, bem como às creches.

Sabemos que as políticas e diretrizes municipais, é que direcionam o atendimento deste público na educação infantil, sendo este nível de ensino o espaço privilegiado para o desenvolvimento intelectual e social através da 
diversidade de estímulos. Acreditamos que, a adoção destas políticas demonstra a vontade e o compromisso com esta clientela, reconhecendo que a qualidade do atendimento ofertado nas creches e pré-escolas está diretamente relacionada com as formas de pensar, organizar e gerir a educação infantil.

\section{REFERÊNCIAS}

BARDIN, Laurence. Análise de Conteúdo. Trad. Luiz Antero Reto e Augusto Pinheiro. São Paulo, Martins Fontes, 1977.

BOGDAN, Roberto C.; BIKLEN, Sari K. Investigação qualitativa em educação. Trad. Maria João Alvarez, Sara Bahia dos Santos e Telma M. Baptista. Portugal, Porto Editora, 1994.

BRASIL. Diretrizes Curriculares Nacionais para a Educação Especial na Educação Básica. Brasilia, CNE/CEB, 2001.

\section{Lei ${ }^{\circ} 8.069 / 90$. Dispõe sobre}

Estatuto da Criança e do Adolescente e dá outras providências. Brasília, 1990.

\section{Lei $n^{\circ}$ 9394/96. Lei de Diretrizes e}

Bases da Educação Nacional. Brasília, 1996.

Ministério da Educação. Instituto

Nacional de Estudos e Pesquisas Educacionais Anísio Teixeira - INEP. Censo Escolar da Educação Básica - 2007. Disponível em: <http://www.inep.govol.br/básica/levantament os/microdados.asp>. Acesso em: 10/04/2014.

. Ministério da Educação. Instituto Nacional de Estudos e Pesquisas Educacionais Anísio Teixeira - INEP. Censo Escolar da Educação Básica - 2008. Disponível em: <http://www.inep.govol.br/básica/levantament os/microdados.asp>. Acesso em: 10/04/2014.

Ministério da Educação. Instituto Nacional de Estudos e Pesquisas Educacionais Anísio Teixeira - INEP. Censo Escolar da Educação Básica - 2009. Disponível em: <http://www.inep.govol.br/básica/levantament os/microdados.asp>. Acesso em: 10/04/2014.
. Ministério da Educação. Instituto Nacional de Estudos e Pesquisas Educacionais Anísio Teixeira - INEP. Censo Escolar da Educação Básica - 2010. Disponível em: <http://www.inep.govol.br/básica/ levantamentos/microdados.asp >. Acesso em: 10/04/ 2014 e em 04/06/2014.

. Ministério da Educação. Instituto

Nacional de Estudos e Pesquisas Educacionais Anísio Teixeira - INEP. Censo Escolar da Educação Básica - 2011. Disponível em: <http://www.inep.govol.br/básica/ levantamentos/microdados.asp >. Acesso em: 10/04/2014.

. Ministério da Educação. Instituto Nacional de Estudos e Pesquisas Educacionais Anísio Teixeira - INEP. Censo Escolar da Educação Básica - 2012. Disponível em: <http://www.inep.govol.br/básica/ levantamentos/microdados.asp >. Acesso em: 10/04/ 2014.

. Ministério da Educação. Instituto

Nacional de Estudos e Pesquisas Educacionais Anísio Teixeira - INEP. Censo Escolar da Educação Básica - 2013. Disponível em: <http://www.inep.govol.br/básica/ levantamentos/microdados.asp >. Acesso em: 10/04/ 2014.

. Ministério da Educação. Plano

Nacional de Educação - 2001/2011. Brasília, MEC, 2001.

. Ministério da Educação. Secretaria de Educação Especial. Política Nacional de Educação Especial na Perspectiva da Educação Inclusiva. Brasília, MEC/SEESP, 2008.

Parecer 17/2001. Diretrizes Nacionais para a Educação Especial na Educação Básica. CNE/CEB - Brasília, 2001.

BUENO, José G. Silveira; MELETTI, Silvia M. Ferreira. Educação Infantil e Educação Especial: uma análise dos indicadores educacionais brasileiros. Revista

Contrapontos - Eletrônica, v.11, n.3, p.278287/set-dez, 2011.

DE VITTA, Fabiana C.F. A inclusão da criança com necessidades educacionais especiais na 
visão de berçaristas. Cadernos de Pesquisa. v.40, n.139, p.75-93, Jan./Abr. 2010.

GOIÁS. SEE/SUEE. Programa Estadual de Educação para a Diversidade numa Perspectiva Inclusiva (PEEDI): educação inclusiva - garantia de respeito à diferença. 1999.

IPAMERI - CIPO. Projeto políticopedagógico. 2013

LIBÂNEO, José Carlos. Educação Escolar: políticas, estrutura e organização. São Paulo, Cortez, 2003.

MELO, Francisco R. L. Vieira de; FERREIRA, Caline C. de A. O cuidar do aluno com deficiência física na educação infantil sob a ótica das professoras. Revista Brasileira de Educação Especial. Marília, v.15, n.1, p.121-140, Jan./Abr. 2009.

MENDES. Inclusão marco zero: começando pelas creches. Araraquara, Junqueira\&Marin, 2010.

PREFEITURA DE ORIZONA. CJD. Projeto político-pedagógico. 2013

\section{CMLC. Projeto político-}

pedagógico. 2013

CMMT. Projeto político-

pedagógico. 2013

Secretaria Municipal de Educação de Orizona Goiás. Plano Municipal de

Educação. 2001.

A inclusão dentro da proposta

pedagógica. 2013

PREFEITURA DE PIRES DO RIO. Sobre

Pires do Rio. Disponível em:

<http://www.piresdorio.go.

gov.br/nossacidadeHistoria.php?nossacidade=

Hist\%C3\%B3ria>. Acesso em: 28 /11/2013.

PREFEITURA DE SANTA CRUZ DE

GOIÁS. EMAL. Projeto político-pedagógico.

2013

Plano Municipal de Educação.

2009.
UNESCO/BRASIL. Educação e cuidado na primeira infância: grandes desafios. Brasília, UNESCO/BRASIL, OECD, Ministério da Saúde, 2002.

\section{Como citar este artigo (Formato ABNT):}

CANUTO, Monica; TARTUCI, Dulcéria. Diretrizes políticas de inclusão escolar que direcionam o acesso na educação infantil em municípios goianos. Educação, Psicologia e Interfaces, vol.1, n.2, p. 14-27, 2017. DOI: https://doi.org/10.37444/issn-2594-5343.v1i2.21

Recebido: 04/11/2017.

Aceito: 22/12/2017. 